\section{Two-pronged approach to T1D}

\section{By Kai-Jye Lou, Staff Writer}

Researchers at the City of Hope have combined a method to regenerate pancreatic $\beta$ cells with a strategy to induce immune tolerance and have used the dual approach to treat advanced type 1 diabetes in mice. ${ }^{1}$ The team plans to validate the technique in other autoimmune diseases before applying it to patients with type 1 diabetes.

Type 1 diabetes (T1D) occurs when autoreactive T cells attack and destroy insulin-producing pancreatic $\beta$ cells. Restoring the body's ability to produce insulin in type 1 diabetes requires regenerating insulinproducing $\beta$ cells and preventing a host immune response against those new cells. The task is even harder in advanced type 1 diabetes, in which few if any functioning $\beta$ cells remain.

In prior mouse studies, researchers led by Defu Zeng developed a regimen to promote tolerance and $\beta$ cell regeneration. The approach involved delivering two types of murine anti-Cd3 antibodies-one that bound the $\mathrm{Fc}$ receptor $(\mathrm{FcR})$ and one that did not-and a murine anti-Cd8a (p32; Cd8) antibody to condition the host immune system for a cell transplant. Treatment with the antibodies was then followed by transplantation of donor bone marrow and spleen cells that were depleted of $\mathrm{Cd} 4^{+} \mathrm{T}$ cells.

The regimen reversed autoimmunity, eliminated islet inflammation and reversed new-onset type 1 diabetes but was unable to augment the generation of $\beta$ cells in advanced type 1 diabetes. ${ }^{2,3}$

Now, Zeng's team has combined the immune-tolerance regimen with a cocktail of two growth factors - gastrin and epidermal growth factor (EGF) - that are known to increase $\beta$ cell regeneration in mouse models and human cell culture. ${ }^{4,5}$

Zeng is an associate professor of diabetes, endocrinology and metabolism and of hematology and hematopoietic cell transplantation at the Beckman Research Institute at City of Hope.

In a mouse model of advanced type 1 diabetes, the immune tolerance regimen plus the growth factor cocktail augmented $\beta$ cell regeneration and restored normal glycemia in 7 of 12 animals for up to 150 days after cessation of growth factor therapy, whereas either treatment alone failed to restore glycemic control in any animal. Mice received daily injections of the growth factor cocktail for up to 60 days.

The immune tolerance regimen eliminated islet inflammation and promoted the survival of newly generated $\beta$ cells. The growth factor cocktail augmented both the generation of $\beta$ cells from progenitors and $\beta$ cell replication.

Results were published in Science Translational Medicine.

"This is a really nice piece of science, well conducted, that combines an approach to promote tolerance toward $\beta$ cells with the regeneration of $\beta$ cells using growth factors," said James Shapiro, director of the Clinical Islet Transplant Program at the University of Alberta. "If such an approach were fully transplated to the clinic, it could have major impact in treatments for type 1 diabetes."

"The exciting part of this study is that the authors are able to show that they could reverse late-stage diabetes in the mouse model," said Ezio Bonvini, SVP of research at immunotherapy company MacroGenics Inc.

\section{Beta testing}

Zeng thinks the combination therapy has potential as both an alternative and a complement to islet transplantation due to its tolerance- and regeneration-promoting properties.

Shapiro was less sanguine about the approach's translational potential.

He thinks the growth factor therapy could be difficult to apply in the clinical setting because gastrin has a short half-life and the regenerative potential of $\beta$ cells in adults with type 1 diabetes is likely to be lower than that seen in the mouse model.

"If you are an adult and have had type 1 diabetes for 30-40 years, your cells probably won't have the same regenerative potential as cells that are only around 18 weeks old, as seen in the late-stage mouse model," Shapiro said.

However, Zeng noted that even if the combination therapy fails to regenerate a patient's own $\beta$ cells and restore glycemic control, it could still promote tolerance toward transplanted islets.

"Our combination approach could provide immune tolerance towards donor islets and improve their function and thus ensure the long-term survival of the graft," he told SciBX.

MacroGenics president and CEO Scott Koenig said it will be important to replicate the findings in model systems that use human cells. "At this time, we can't necessarily conclude that the regenerative component that they've included in their protocol would reconstitute human $\beta$ cell function," he told SciBX.

Shapiro also wanted to see additional safety data on the antibodies used in the tolerance-inducing regimen. He noted that the FcR-binding property of anti-CD3 mAbs such as Orthoclone OKT3 muromonab is linked with their serious adverse effects such as cytokine release syndrome and risk of lymphoproliferative disorders. He said there may be other antibodies that could be substituted that would not carry such risk.

Johnson \& Johnson marketed Orthoclone to treat glucocorticoidresistant organ transplant rejection but discontinued manufacturing of the $\mathrm{mAb}$ in 2010 for competitive reasons. 
Zeng said his group is considering using Orthoclone as the FcR-binding anti-CD3 antibody in the conditioning regimen but acknowledged it could be challenging as the $\mathrm{mAb}$ is no longer commercially available. The group has not yet determined which

\section{"The exciting part of this study is that the authors are able to show that they could reverse late-stage diabetes in the mouse model." \\ -Ezio Bonvini, MacroGenics Inc.} anti-CD8 and non-FcR-binding anti-CD3 antibody it will use.

Zeng said the group plans to produce the antibody at a GMP facility.

Non-FcR-binding anti-CD3 mAbs that have been tested for type 1 diabetes include MacroGenics' teplizumab. ${ }^{6}$

Teplizumab missed its primary endpoint in a Phase III trial in patients with recentonset type 1 diabetes, although it did have a safety profile that looked better than Orthoclone's.

Teplizumab now is being evaluated in a Phase II/III trial to prevent type 1 diabetes in at-risk individuals - those who show abnormal glucose tolerance, express at least two known diabetes-associated autoantibodies and have a first-degree relative who has the disease. The NIH's National Institute of Diabetes and Digestive and Kidney Diseases (NIDDK) is sponsoring the trial.

\section{Translational roadmap}

Zeng said his group first needs to test its tolerance-promoting regimen in disease settings that are more severe and thus have lower safety bars than type 1 diabetes.

First, the team plans to test whether the antibody-conditioning regimen can prevent graft-versus-host disease (GvHD) in patients with hematological malignancies who will be treated with a bone marrow transplant. At the same time, they plan to test the antibody regimen followed by the transplantation of bone marrow and spleen cells in nonhuman primates to confirm the protocol itself does not cause GvHD, which is a complication of bone marrow transplant.
Finally, the researchers will test the antibody regimen followed by transplantation of bone marrow and spleen cells in patients with multiple sclerosis (MS) and lupus before moving into type 1 diabetes.

For the growth factor component, Zeng said the group is looking to optimize the combination of growth factors and hormones that could augment $\beta$ cell regeneration beyond what was seen with the EGF-gastrin cocktail. "We want to identify combinations that could further increase response rates and reduce treatment times," he told SciBX. "We would like to identify a cocktail that could reduce treatment times down to one month from two months and increase the response rate above the $60 \%$ we've seen in mouse models thus far."

As the mechanism of $\beta$ cell regeneration is unclear, Zeng said the group also plans to carry out lineage-tracing experiments to determine the progenitor cell population in the pancreas that gives rise to new $\beta$ cells and then develop strategies to expand such cell populations.

City of Hope has filed a patent application covering the conditioning regimen for promoting immune tolerance. The work is available for licensing.

Lou, K.-J. SciBX 5(23); doi:10.1038/scibx.2012.588

Published online June 7, 2012

\section{REFERENCES}

1. Wang, M. et al. Sci. Transl. Med.; published online May 9, 2012; doi:10.1126/scitransImed.3003835

Contact: Defu Zeng, Beckman Research Institute at City of Hope, Duarte, Calif. e-mail: dzeng@coh.org

2. Zhang, C. et al. Proc. Natl. Acad. Sci. USA 104, 2337-2342 (2007)

3. Zhang, C. et al. Diabetes 59, 2228-2236 (2010)

4. Suarez-Pinzon, W.L. et al. J. Clin. Endocrinol. Metab. 90, 3401-3409 (2005)

5. Suarez-Pinzon, W.L. et al. Diabetes 54, 2596-2601 (2005)

6. Masharani, U.B. \& Becker, J. Expert Opin. Biol. Ther. 10, 459-465 (2010)

\section{COMPANIES AND INSTITUTIONS MENTIONED}

Beckman Research Institute at City of Hope, Duarte, Calif. Johnson \& Johnson (NYSE:JNJ), New Brunswick, N.J.

MacroGenics Inc., Rockville, Md.

National Institute of Diabetes and Digestive and Kidney

Diseases, Bethesda, Md.

National Institutes of Health, Bethesda, Md.

University of Alberta, Edmonton, Alberta, Canada 